\title{
A REVIEW OF CHRONIC PROGRESSIVE CHOREA (HUNTINGTON'S), WITH REPORT OF A CASE.
}

\author{
By ClARENCE A. GOOD, M. D.,
} Northern Michigan Asylum.

(From the Pathological Department of the Michigan State Asylums for the Insane.)

The literature of chronic progressive chorea dates back to 1842 , when Dr. C. O. Waters, of Franklin, N. Y., in a letter to Dr. Dunglison, described a peculiar form of chorea infesting certain families of that locality. Dr. Waters characterized this disease as peculiar in four ways: I. In being markedly hereditary; 2. Rarely appearing before adult life, or after 45 ; 3 . It was incurable; 4. It always induced dementia. The disease was known among the common people as "megrims." Dunglison inserted the letter in his Third Edition, with the remark that he had never seen the disease. Dunglison also states that attention was called to a similar disease by Dr. Charles Gorman, of Luzerne, $\mathrm{Pa}$., in his inaugural address before the faculty of the Jefferson Medical College.

Dr. Irving M. Lyon (I) in 1863 next gave a description' of the disease. He noted its heredity and that it only occurred in certain families. He does not note any mental affection as occurring with it, and in several instances states that it began in early childhood. He reports two cases in which three generations were affected and one in which four generations were affected. One brother of this last case, who was not himself affected, had two children "in whom well-defined chorea had existed for years."

Huntington (2), in 1872 , in a postscript to an article on chorea minor, gave an admirable description of hereditary chorea. This article caused considerable interest to be taken in the disease, and since this time it has been quite generally known as Hunt- 
ington's Chorea. Huntington's father and grandfather had practiced medicine in the eastern end of Long Island for seventyeight years and had been acquainted with certain families in which chorea had existed for generations. Huntington believed that the disease was peculiar to Long Island. He noted that the disease affected males more than females; that it came on gradually, always after middle life, and was incurable; and that it was usually accompanied by insanity and a tendency to suicide. $\mathrm{He}$ also adds that if one of the family escape the disease his descendants are ever after free.

Ewald (3) described two cases in different families. The disease was hereditary, but in neither case was the mind affected. Clarence King (4) reported a family history in which the grandfather was choreic. Of his ten children four had chorea. Three of these had children who also had chorea. The fourth had nine children, one of whom was affected, and of the five children of this latter all developed chorea-making in all four generations with nine known individuals affected.

Dr. S. C. Stevens, in a paper before the South Carolina Medical Association, reported two brothers, one eleven, the other twelve years old, one of whom had been choreic since birth, the other developing the disease during his first year. They belonged to a family in which hereditary chorea had existed for several generations.

Peretti (5) reports a most interesting family. Frau N., who was choreic, had four children, two of whom were diseased. Of the fifteen children of these two, nine had chorea and four others had nervous affections. Of these nine, one had four healthy children over thirty years old, and three of these had healthy children; four others had children among whom there were three affected, one at the early age of twenty-three. He noted insanity as occurring four times.

Huber (6) reports a case beginning at the age of thirty. This man's sister at 42 was choreic and demented; his father was choreic and insane, and his father's sister was choreic. Autopsy revealed a cerebral pachymeningitis.

West (7) reported a family in which three generations were affected, and Zacher (8) describes a case in whose family four generations were affected. 
Hoffman (9) reports some cases among whom one became affected at the early age of ten years. He also has called attention to the similarity existing between general paralysis of the insane and Huntington's chorea.

Macleod (Io) reported two sisters who were choreic and insane. Two brothers are said to be choreic, as is also the father. The pathology of these cases is peculiar and will be described later.

Lannois' (I I) article gives an excellent description of six cases he has had occurring in a family in which four generations were affected. He also gives a complete review of the subject and literature up to date.

Suckling (12) reports a case in a man coming on at the age of thirty-five years. He had been previously healthy. The choreic movements were general. There was a "sniffing" due to involvement of the diaphragm. Speech and knee-jerk were normal. The man's mother died choreic and helpless at the age of fifty-six. Had been choreic for sixteen years. Suckling also saw a sister of the man, who, at thirty-eight, had been affected for five years. This woman's daughter, age twelve, was also affected with the disease.

Diller (13) reports seven cases from the State Hospital for the Insane at Dansville, $\mathrm{Pa}$.

CASE I was 62 years of age; had been choreic for two years; choreic movements general; cease during sleep; mentally, patient was irritable and childish. For a short time previous to his death the movements became less frequent and intense on right side. Autopsy revealed under the dura of vertex and sides of left hemisphere a cyst lined "with a thick and dark-colored false membrane," which extended over the posterior part of the frontal and the whole of the parietal lobes. The convolutions under the growth were depressed and flattened. Large gliomatous bodies were found on the choroid plexuses.

CASE II. Widow, age 72; sister of previous patient; choreic for two years; movements general and cease during sleep; great mental stupor; paralysis of both legs. The autopsy revealed several tumors in the dura mater; the largest the size of a chestnut. These tumors produced distinct depressions at the roots of the first and second frontal convolutions and upper parts of the ascending frontal and ascending parietal convolutions. They 
caused a thinning but not a destruction of the underlying cortex. The tumors were of a hard, scirrhous nature. The arteries were atheromatous.

On considering the lack of family history, the age at which the disease began, the length of time it existed before causing death, and the paralysis existing in one case, I think there is considerable doubt whether these are really cases of Huntington's chorea. Their pathology is also peculiar, and I believe them to be cases of chronic chorea due to cortical lesions and to resemble athetosis and post-paralytic chorea.

Diller also reports four other cases, in all of whom there was a family history of the disease. In one instance eleven undoubted cases occurred in three generations.

Herringhan (14) in I889 wrote an article on "Chronic Hereditary Chorea," reviewing the literature up to date. In the same year he also wrote on the "Chorea of the Adult and of the Old." In this he makes four divisions of chronic chorea of adults: I. Chorea like Sydenham's; 2. Chorea from sub-cortical lesions, the pathology usually consisting of a patch of softening either pressing on the posterior part of the internal capsule behind the motor tract, as in a case reported by Charcot, or in front of the motor tract, as in Gee's case; or again, of a patch of softening entirely within the optic thalamus, as in the case of Gowers and the case of Galvagni; 3. Hereditary chorea (Huntington's) accompanied by dementia; 4 . Chorea differing from the first in being chronic and from the second in the lesion being cortical, and from the third in lacking the element of heredity. In these cases there have been found pachymeningitis, leptomeningitis, subarachnoid hæmorrhages, subdural cysts over motor area, etc.

Bower (I5) reports three cases. Case I was in a negro. The disease began at thirty. He had been a hard drinker and had a history of paraplegia at 28 , lasting three months. His movements were characteristic. His speech was slow and hesitating. This patient's mother and her two sisters had chorea. Case II had all the characteristics of the disease excepting the lack of a history of heredity and the mental disturbance. Disease began at 29. Case III became choreic at 36. His father was choreic, and his baby, four months old, has constant twitchings of the hands. 
Hay (I6) reports eight cases from the asylum at Morris Plains, N. J. All had a family history of the disease. In one case choreic movements did not begin until her sixtieth year. The daughter of one of his cases became choreic before the age of 20 .

Sinkler (17) reports three cases with one autopsy. His findings will be noted later. He reached the following conclusions: I. The disease is markedly hereditary, but a few characteristic cases lack this heredity; 2. Most cases begin between the ages of 35 and 50 years; 3. Mental disease occurs in most cases and may precede or follow the choreic movements.

Dercum, in 1892 , wrote a review of Huntington's chorea. In his Text-Book of Nervous Diseases he gives an excellent description of the disease with numerous references. He also pictures one of his cases.

Reynolds (18) reports two cases. Case I became affected at the age of 3o. Both maternal and both paternal grandparents, his mother and his sister, were choreic. The muscles of the head, face and neck were most affected. Case II became choreic at 53. Movements began shortly after patient sustained a fall, striking on his head. His father became choreic at 60 and died one year later.

Phelps (19) reports thirteen cases which he has collected from various asylums. Many of these presented the characteristic symptoms of hereditary chorea, yet did not have a history of heredity. He calls special attention to this fact. He also calls attention to the similarity existing between hereditary chorea and general paralysis, the points in common being thus summarized: I. Begins in adult life. 2. Mental change is essentially a dementia. Many of the choreics are irritable and violent and possess exaggerated ideas. 3. Motor appearances; toward the last the facial sluggishness, the clumsy use of face and hands, feet and tongue, and the general physical and mental helplessness presenting almost the same clinical appearances. 4. Duration in chorea two or three times as long as in paresis, yet the more gradual mental and physical invasion might account for the lack of so pronounced an excited stage. 5. The progressive and uniformly fatal character of the disease.

Gray (20), in the second edition of his Text-Book on Nervous Diseases, gives and pictures a case of his which he considers one of congenital Huntington's chorea. 
Osler (21), in an article on the Varieties of Chronic Chorea, reports two cases which he has had. In both there was a marked family history of the disease. He secured an autopsy on one case, and his finding will be noted later. Osler makes the following divisions of chronic chorea: I. Chorea of infants. Begins at birth or during second or third years of life. In this are found four classes: (a) spastic diplegia with choreiform, tremulous or athetoid movements; (b) spastic paraplegia with choreiform and athetoid movements; $(c)$ chronic chorea; $(d)$ chronic progressive chorea with dementia. 2. Chronic progressive chorea without any hereditary anlage. He states that this may begin in childhood, adolescence, maturity or old age. 3. Chronic hereditary chorea, Huntington's. 4. Cases of chorea minor that persist for months or years but finally recover.

Dana (22) reports a most interesting case and describes in detail the microscopical findings in the brain. This part of his paper will be referred to later. John C. was 37 at the time of his death. $\mathrm{He}$ had been affected for four years. The disease began without any exciting cause, first appearing as a slight disturbance in articulation. As the disease progressed the head, arms and legs became affected. His gait was of the loping or high-stepping variety. Shortly after the disturbance of speech began his mind became affected. He was easily excited and irritable. His memory failed and he became unable to do his ordinary work, which was that of a peddler. There was no nystagmus, no paralysis or atrophies, no pains or anæsthesias, and no trophic disturbance of the skin. Lungs, heart, kidneys and digestive tract were normal. About a year and a half before his death the patient was trephined by Dr. Dana. For six months after the operation he was better, but then relapsed into his former condition. He died of typhoid fever in the fourth year of the disease.

This patient's great-great-grandmother, his great-grandmother, his grandmother and his mother were choreic, his mother developing the disease at 30 and dying at 40.

We may now enter into a description of the disease. Hereditary chorea, as the name implies, is essentially a hereditary disease, the same form of disease having existed in the parents, 
grandparents, etc. The disease may be transmitted through the female, as in Dana's case, or through the male, as in Huber's case, probably most frequently through the female. Huntington noted as early as 1872 that if the chain was once broken and any member escaped, his descendants were ever after free from the disease. This fact has been corroborated by numerous observers since his time. Lyon, however, reports an exception to this general rule.

The disease usually begins in adult life, the majority of the cases occurring after 35. Yet, as we have seen, Hoffman reports a case at 10, Hay at 20, Suckling at 12, and Gray and Stevens have each reported a congenital case. Huet (23) in $1889 \mathrm{col}$ lected 67 cases, the age of the onset being as follows:

$\begin{array}{lrlr}\text { I0 years, } & \text { I } & 35 \text { to } 40 \text { years, } & \text { I3 } \\ \text { I0 to I5 years, } & \text { I } & 40 \text { to } 45 \text { years, } & \text { I I } \\ \text { I5 to } 20 \text { years, } & 2 & 45 \text { to } 50 \text { years, } & 7 \\ 20 \text { to } 25 \text { years, } & \text { I } & 50 \text { to } 55 \text { years, } & 8 \\ 25 \text { to } 30 \text { years, } & 5 & 60 \text { to } 65 \text { years, } & \text { I } \\ 30 \text { to } 35 \text { years, } & \text { I6 } & 65 \text { to } 70 \text { years, } & \text { I }\end{array}$

As many males as females are affected. The disease develops insidiously and without any known cause by twitchings in the face (King, Huber), difficulty in articulation (Dana), spreading thence to arms and legs, or is general from the outset (Hoffman). The choreic movements are never localized, after the disease has progressed for any length of time. The movements are more extreme, coarse and non-rhythmical than in either Sydenham's chorea or in athetosis.

These movements are at first partially under the control of the will, but this is soon lost. They are always more violent when the patient is talking or is watched, and always cease during sleep. Fatigue is never complained of.

Speech is invariably involved quite early in the disease, sometimes being thick, or again the words being indistinctly or hesitatingly pronounced. Deglutition becomes difficult, especially in the later stages. The gait is usually described as of the loping or dancing variety; that is, the patient takes a few long steps naturally, then makes a long step with one leg, bringing up the other quickly to it, then making one or two hops. In many of the cases, however, the gait is simply awkward and uncertain. 
In chronic progressive chorea there is no wasting of muscles other than that occurring in the general emaciation. There is no anæsthesia, and the reflexes are normal or slightly exaggerated, as in Osler's case. The reaction of the muscles and nerves to electricity remains normal. The bodily functions are carried on normally, so that for several years, or until the mental enfeeblement has considerably progressed, the patients are able to be about and to perform their duties. The acts of defecation and micturition, as long as the mind is not enfeebled, are properly performed and the sexual functions remain normal; in fact, many of the women are especially prolific. Sooner or later in the progress of the disease the mind becomes affected. This is noted by practically all writers on hereditary chorea. Clarke (29) reports a family history in which in three generations, out of fourteen individuals five had chorea and eight were insane and had been in asylums. The mental affection may develop synchronously, and may precede or may follow the choreic movements. In the great majority mental changes are noted at the time of the beginning of the twitchings, or shortly thereafter. The most common and characteristic form of mental change is a gradually progressing dementia. This is often accompanied by a distinct depression. Gray, among others, is inclined to think this depression is due to the fact that the disease is known to be hereditary and fatal in the families affected. In some cases there is a distinct suicidal tendency. While the common mental alienation is a dementia, many of the cases are excitable, irritable, and subject to violent outbursts of anger. This was especially noted by Dana and Diller. Accompanying this mental enfeeblement there are often delusions of persecution or of grandeur. Although the majority suffer from dementia, there are cases that retain their mental capacities till the end. Sinkler has called special attention to this fact. As the disease progresses the movements become more violent and less under the control of the will, until the patient is unable to stand alone or to feed himself; the dementia progresses and becomes absolute and the patient is confined to his bed, and finally dies of exhaustion. The disease is very chronic, in many cases lasting 10,15 and even 20 years.

In the literature the pathology of Huntington's chorea is not considered nearly as fully as the history and clinical considera- 
tions; in fact, the number of recorded autopsies are few indeed and the recent text-books have nothing definite concerning the pathology.

Huber has recorded a cerebral pachymeningitis. Macleod, in one case, found pachymeningitis and a hæmatoma of the left hemisphere involving most of the parietal and the posterior part of the frontal lobes. In another case he found several tumors in the dura covering the left hemisphere, particularly over the motor region, and atheroma of the vessels. In still another case he found hæmatoma of both hemispheres involving the parietal and posterior parts of the frontal lobes. There were also gliomatous bodies in the choroid plexuses. Herringhan, in speaking of these cases, says they are exceptional in many ways and the family history is insufficient. I do not think there is any doubt but that they belong, along with Diller's two cases, to a class of chronic chorea due to gross cortical and subcortical lesions.

Berkley (24) reports the case of a woman who became choreic at the age of 35 , five hours after being severely frightened by a murder committed before her. She became demented and died at 4I. Examination showed "dilatation and thickening of arterioles; small gangrenous spots around many vessels; amyloid corpuscles in the lymph sheaths; vacuoles in the white and gray matter; varicosities of sheaths of Schwann and absence of axiscylinders in the nerve fibres; and complete pigmentary degeneration of the cortical and ganglionic cells, with loss of prolongations." Although this case is often given under hereditary chorea, I think it may reasonably be considered a doubtful case.

Dercum found in the spinal cord of a case he examined " an increase of the connective tissue in the white matter with a thickening of the vessels. The region of the central canal was occupied by a mass of nuclear tissue much more abundant than in normal cords."

Greppin (25) reports a case of a man who became choreic at 50 and died demented. In his family there was a history of "chorea, insanity, brain and spinal disease." The autopsy showed pachymeningitis, leptomeningitis and flattening of the convolutions of the brain. Throughout the gray and white matter he found "accumulations of cellular elements, with not 
much developed membrane composed of granular nuclei, so that here and there the ganglion cells and nerve tubes were completely obliterated by them. In some places the cells had degenerated and left a deformed mass." Osler found in his case turbidity of the arachnoid with considerable serous exudate separating the arachnoid from the pia. The arteries at the base were a little stiff. There was a general wasting of the convolutions, which also on section were rather firm. Microscopical examination revealed thickening and hyaline degeneration of the vessels and fatty changes in the arterioles. The perivascular spaces were enlarged and contained leucocytes. The ganglion cells showed slight changes, these not being more severe than a chronic dementia. The pons and cord were practically normal.

In conclusion, Osler expresses the opinion that the morbid anatomy of chronic chorea is a neuro-degenerative disorderdiffuse changes in vascular, ganglionic and neurogliar tissues not essentially different from, though less pronounced, than those of paralytic dementia. Sinkler, in an autopsy made by him, found the dura adherent and thickened; the meninges congested and considerable œdema. In the cord he found an increase of the connective tissue in the white matter except in the posterior columns, which were normal. The axis-cylinders were lessened, but never enough to completely cut off the tract. The region of the central canal was occupied by a mass of cells like those found in normal cords, but the mass was much larger and stained more deeply.

Dana made an autopsy in a case which died of an intercurrent affection (typhoid fever) in the fourth year of the disease. His findings were as follows: The intestines showed the lesions of typhoid fever; the heart was small; the wall of the right ventricle thin and the muscle pale; lungs, spleen and liver practically normal.

The dura was found thickened and adherent; brain itself was congested; not much œdema. The brain was hardened in Müller's fluid. An examination of the surface of the brain showed an absence of the superior pli-de-passage on one side, also an interrupted fissure of Rolando. Dana made many measurements of the thickness of the cortex. He found it almost universally atrophic, but most reduced in the motor region. 
Microscopical examination revealed abnormal changes only in the central and, to a less extent, in the frontal convolutions. These showed a decided thinning of the gray matter, but no particular meningitis. The vessels were slightly thickened. Some sections showed few changes, but others revealed extensive degeneration, atrophy and even disappearance of the ganglion cells, more especially of the angular and small pyramidal layers. In certain regions nearly every pyramidal cell had from one to three small scavenger cells in the pericellular space apparently fixed to the cell. Occasionally a high degree of vascularity of the parts was observed. Dana does not consider the process in any sense inflammatory, but considers that it belongs to teratology and is an innate defect in cell structure. Dercum, in his text-book, also advances this idea.

Facklan (26) reported eight cases with one autopsy. He sums up the pathology of his case as follows: It seemed to be an inflammation of the membranes starting about the blood-vessels and extending into the cortex and characterized by proliferation of the perivascular connective tissue and slight hæmorrhages. The lesion is essentially a chronic hæmorrhagic meningoencephalitis with consequent atrophy of the cortex. He also noted marked proliferation of the muscle nuclei, probably a functional result.

Oppenheim (27), in two cases, found the gyri narrowed and the sulci broadened in the motor, parietal and occipital regions. In these regions there were hæmorrhagic infiltrations in the subcortical layer. In the cortex the small round cells next below the cortex were reduced in number. The pyramidal cells were normal. Oppenheim considers the essential pathology to be miliary encephalitis, cortical and subcortical, followed by atrophy of the cortex. Both of his cases died of infectious diseases-one of influenza.

Kronthal and Kalischer (28) examined three cases, and conclude that the pathology consists of diffuse, rarely circumscribed changes in the cortex. These are diseases of vessel walls, increase of nuclei, cell accumulations, small hæmorrhages and increase of the interstitial framework. The nervous elements are only slightly affected.

Clarke (29) examined two cases and thus summarized his find- 
ings: "The morbid change consists of a widespread but partial degeneration of the cells of the cerebral cortex, especially the cells of the second and third layer, most marked in the frontal and motor convolutions, together with an increased amount of interstitial tissue and number of neuroglia cells."

I will now describe a case which occurred in the Northern Michigan Asylum at Traverse City.

B. E. B. was admitted into the Michigan Asylum at Kalamazoo in April, 1892. He was 45 years of age, married, lawyer with collegiate education. The history which accompanied this patient states that his parents were natives of New York. No history of insanity or chorea was obtained. Ten years prior to his admission he developed chorea and mental failure, the latter being noticed particularly in his silly expressions in the court room. His mind steadily but gradually failed and he was unable to earn a competence. For five years he was supported by his wife, but she finally deserted him and he then acted as a chore boy in a barn. Upon the death of his employer he began to wander about the country, and was committed to the asylum. At the time of his admission he was fairly well nourished. The choreic movements were pronounced, being more marked in right arm and leg. He did not realize the change in his manner of living, and seemed pleased with the prospect of asylum life. He was still able to read and enjoy games. He was sociable and kind. His general demeanor was one of simplicity. $\mathrm{He}$ was transferred to the Northern Michigan Asylum in 1896. After his admission his mind gradually became feebler and his choreic movements more marked. His eyes would roll in their sockets, his brow wrinkle and his tongue protrude; his head would te turned and twisted and his legs and arms go through strange and varied contortions. These, coupled with his queer grimaces, made him a sight to rivet the attention of one not accustomed to see him. In September, 1898 , his movements became so violent he could no longer walk nor feed himself, and he had to be put to bed. His movements were much more severe when he attempted to talk or when he was watched. The knee-jerk was normal. Cutaneous sensibility remained normal as long as patient's mind was not so much enfeebled as to make the examination unsatisfactory. He became feebler, deglutition became 
very difficult, and he finally died of exhaustion December I7, 1898. Autopsy four hours after death. Protocol: Body of a man of medium height and rather slight frame. Marked emaciation. No trophic sores. No rigor mortis, neither was this present at any time later. No localized atrophies.

Cranium: Calvarium thick and heavy, there being practically no diploë. Dura thickened and very adherent to skull-cap, rendering its removal difficult. When the dura was removed the brain and membranes presented the appearance ordinarily presented in general paralysis, viz., the arachnoid was thickened and milky; in the pia, which was thickened, there were white streaks following the course of the blood-vessels, and the arachnoid was universally flooded up from the pia by a syrupy, straw-colored fluid. This fluid was in abundance. The vessels were moderately dilated. Pacchionian bodies large. The base of the brain appeared normal. Slight atheroma of vessels. The pia was not adherent to the cortex. The brain at a glance was seen to be atrophic, the gyri small, the sulci wide and gaping. The weight of the brain with the pia was $33.5 \mathrm{oz}$. The convolutions in the motor and frontal regions seemed most atrophic. Ventricles were moderately dilated. Ependyma normal. A careful study of the surface of the brain revealed no abnormality in the arrangement of the fissures. The medulla and pons appeared normal on cross section, as did the cord, except that in the lower cervical region the gray matter appeared bloody.

Several posterior root ganglia, sections of the sciatic nerves and parts of the following muscles, viz., intrinsic muscles of the foot, intercostals and pectoralis major, were removed.

The lungs were normal. The heart was small with evidences of old pericarditis. Ventricular walls thin, valves normal. The liver was small, dark-colored, and firm on section. Blood content increased. Small cyst under capsule on convex surface. Spleen small and firm. The kidneys were small, and both were lobulated. On section the cortex and medulla presented no marked abnormal appearances. The stomach and intestines were normal. Testes atrophic; neither epididymis showed any thickenings.

The tissues were treated as follows: Thin slices from various regions of the brain were placed in a one per cent solution of 
osmic acid for 24 hours and after-hardened in alcohol; others were placed in absolute alcohol, and still others were hardened in successive grades of acohol; but by far the greater part of the brain, together with the pons, medulla, cord, nerves, muscles, thoracic and abdominal organs, were preserved in Müller's fluid. Some of the posterior root ganglia were preserved in alcohol, while others were treated with osmic acid. Bits of the muscles were treated according to Ranvier's gold-chloride method to show the nerve terminations in the voluntary muscles.

After the brain had been in Müller's fluid long enough to become quite firm and to differentiate clearly the white from the gray substance, about one hundred measurements were made of the cortex, always at the convexity of the convolutions. The following table, which is in millimeters, will show the averages, and will compare these with the measurements of the normal cortex.

\begin{tabular}{|c|c|c|}
\hline Frontal & $\begin{array}{l}\text { This case. } \\
\text {. } 2.71\end{array}$ & $\begin{array}{l}\text { Normal. } \\
3.1\end{array}$ \\
\hline convolutions & 2.49 & 2.75 to 3 \\
\hline oral $\ldots \ldots \ldots$ & 2.8 & 3.1 \\
\hline Occi &. .2 .4 & 2.5 to \\
\hline
\end{tabular}

The following stains were used: For the study of the cortical cells and cortical structures Nissl's, osmic acid, hæmatoxylin and Van Gieson's. The basal ganglia were also stained with these stains. For the study of the peripheral nerves, cord, medulla, pons, and conduction paths of the brain, Van Gieson's and Weigert's methods were used; for the study of the posterior root ganglia, osmic acid and Nissl's; for the study of the muscles, hæmatoxylin and eosin and the gold-chloride method; and for the thoracic and abdominal organs, Van Gieson's.

By the use of Ranvier's gold-chloride method I was able to demonstrate several nerve terminations in the intrinsic muscles of the foot, and so far as I could determine they were normal. The muscles in various places showed degenerative changes. The cells are of irregular sizes, some being swollen and vacuolated, while others are small. Others again are more or less broken up and finely granular, and the striations are lost. Some cells take the eosin stain normally, others stain very poorly, while still others 
take the stain deeply and have a decided bluish cast. These latter cells appear homogeneous and waxy (Fig. I). Sections of the lungs, heart, liver, spleen and kidneys, presented no marked pathological changes. With Weigert's method I could demonstrate no degenerations of the peripheral nerves. The cells of the posterior root ganglia were of normal number and size, but nearly all of them contained an enormous amount of large pigment granules heaped up within the cells, sometimes surrounding the nucleus, at other times occupying one side of the cell, but rarely distributed throughout the cell. This pigment appeared yellow unstained, and took osmic acid black (Fig. 2).

The spinal cord shows throughout an enormous number of corpora amylacea. These are found throughout the white and gray substance, being more numerous in the white substance. One anterior horn is larger throughout the whole length of the cord than the other. Nissl's stain does not show any particular changes in the cells of the cord. In the lower cervical regions there are a few capillary hæmorrhages into the gray matter. Weigert's method shows that there is no system degeneration, though there is a material lessening of the axis-cylinders in the region occupied by the direct pyramidal tracts, but in no sense being sufficient to cut off the tract. Throughout the medulla, pons and midbrain there are no appreciable changes.

Marked pathological changes were found in the cerebral cortex. In the left post-central convolution about in the region occupied by the arm center, 6 or 8 small cysts were found. These varied in size from $1 / 4$ to $3 / 4 \mathrm{~mm}$. in diameter, and were situated either just beneath the pia or in the region occupied by the pyramidal cells. The cysts did not possess a lining membrane and the walls are smooth and regular. The ganglion cells extend directly to the edge of the cysts, which are probably to be regarded as greatly dilated lymph spaces (Fig. 3). Throughout the motor regions there existed most extensive cell degeneration. With the osmic acid method many of the cells of the molecular layer and the layer of small pyramidal cells are filled with large and small granules, stained black. In some places the cell has completely disintegrated, and in its place is found a mass of granules which stain black and perhaps one or two scavenger cells. With this method the walls of the smaller vessels are also 
seen to be undergoing fatty degeneration. With Nissl's stain the cellular degeneration is well brought out. The cells of the small pyramidal layer are mostly affected, although many of the large pyramidal cells are degenerated. In some fields there is hardly to be seen a normal looking cell, many being extensively vacuolated and the most of them taking the stain diffusely. The processes of many of the cells are shrunken and irregular. Some cells are completely broken down, leaving only a mass of granular débris, while in others the cell form is retained, but the nucleus has disappeared. In many of the pericellular spaces from 2 to 6 scavenger cells fixed apparently directly to the ganglion cells and often making a distinct depression in its side, can be seen. In some fields many of the cells have disappeared, leaving small, clear spaces, which give a reticulated appearance to the specimen. The number of glia cells in the outer layer of the cortex is considerably increased. These changes are distributed quite generally throughout the motor region, yet areas are found where the cells are tolerably well preserved. Changes similar to the above, though less severe, are found throughout the whole cortex, the frontal lobes suffering most severely next to the motor regions.

The vessels quite generally throughout the brain are dilated and filled with blood, but there are no extravasations. In places the cells of the vessel walls have begun to proliferate, but this change is not at all marked. The connective tissue throughout the brain is only slightly increased. In the white substance of the brain, in the basal ganglia $a_{2}$ and in the cerebellum, I could find no appreciable changes.

A careful examination of the entire nervous system of this patient does not show any evidences of a primary inflammation, or involvement, primarily, of the supporting framework of the system. On the other hand, there existed throughout the cortex overwhelming evidences of the involvement of the ganglion cells most marked in the motor and frontal regions. This degeneration may affect the motor regions primarily, but I suspect that it also involves other parts, as the early and progressive dementia would indicate. Certainly in the later stages there is an involvement of other parts of the cortex than the motor areas. This 

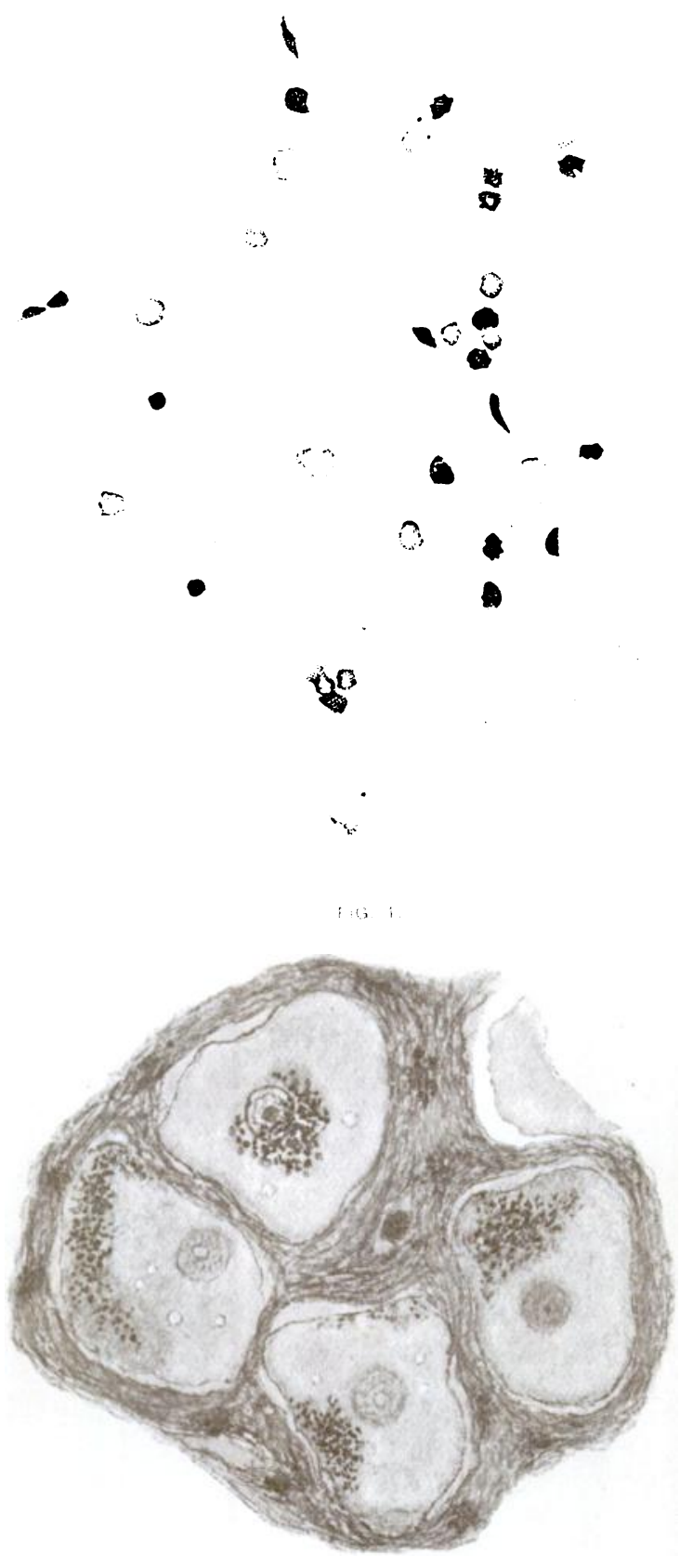


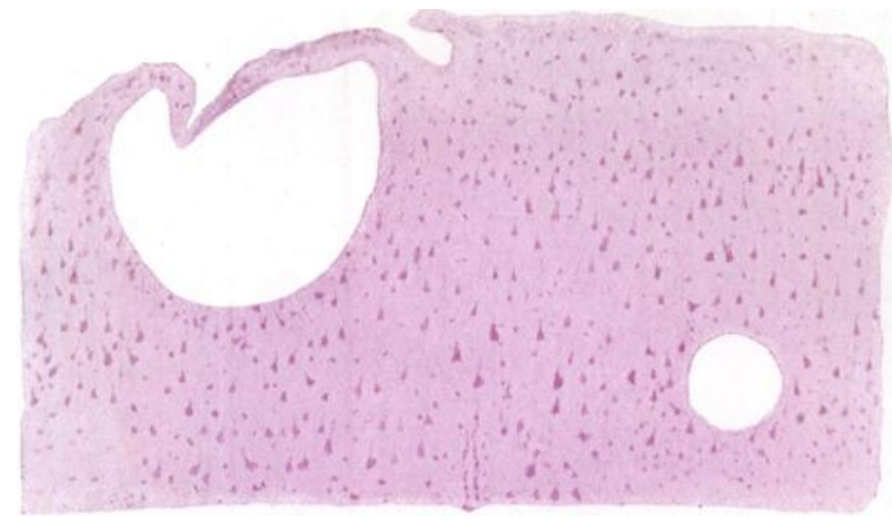

FIG. 3 .

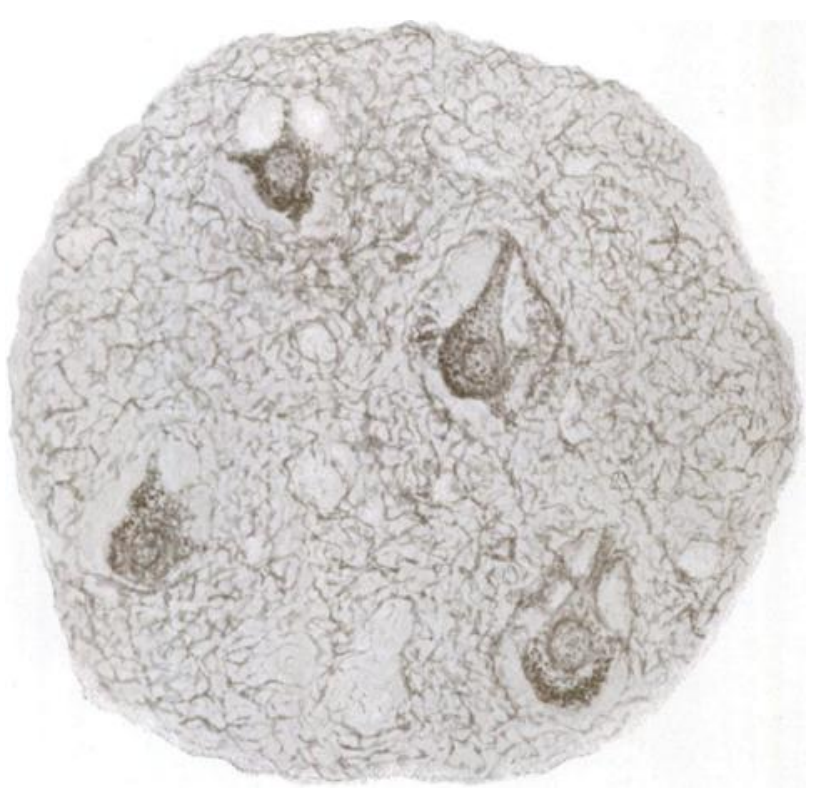

Fili.: 
cell degeneration is of the common form and gives rise in its progress to fatty changes and fat granules.

\section{Description OF Figures.}

Fig. $I$ is a drawing from a cross section of one of the intrinsic muscles of the foot, stained in hæmatoxylin and eosin. In the center of the figure several fibers are seen which take the stain very poorly and whose outline it is difficult to make out. To the right of the center is seen a fiber whose protoplasm is finely granular, and which contains in its center two large vacuoles. In the upper part of the figure are seen two S-shaped fibers, one taking the stain deeply and the other faintly; their protoplasm is finely granular. In sections cut lengthwise to these fibers they showed an entire absence of striations. In the upper left part of the figure is seen a large fiber whose protoplasm appears homogeneous and takes the stain deeply. Between the degenerated fibers the nuclei of the connective tissue are considerably increased.

Fig. 2 represents four cells from a posterior root ganglion treated with osmic acid. Heaped up within the cell is seen a large amount of coarse black granules. Some of the cells contained small vacuoles, and in one the nucleus is situated at the periphery of the cell.

Fig. 3 is a drawing from a section of the left post-central gyrus stained in a concentrated watery solution of Fuchsin. It shows two of the cysts found in that region.

Fig. 4 is a drawing of a section from the left post-central gyrus treated with osmic acid. It shows four cells, each containing a large amount of pigment granules which stain black. These granules can also be seen in the pericellular spaces. Near the bottom is a space from which the cell has disappeared.

\section{REFERENCES.}

I. Am. M. Times, N. Y., Dec. 19, 1863.

2. Med. and Surg. Reporter, Apr. 13, 1872. Quoted by Sinkler in Pepper's System, vol. V, 440.

3. Ztschr. f. klin. Med., 1884, VII, Suppl. H, 5 I.

4. N. York M. J., Apr., 1885, vol. XLI, 468.

5. Berl. klin. Woch., I885, No. 52. 
6. Virch. Arch., CVIII, 1887, 267.

7. Brit. M. J., Lond., 1887, 425.

8. Neurolog. Centralblatt, I888, 34

9. Virch. Arch., 1888, 513.

10. Jour. Ment. Sci., Lond., XXVIII, 1882, 194.

II. Rev. de Med., VII, 1888, 645.

12. Quoted in Practitioner, Nov., 1889, from Birmingham Med. Review, Sept., 1889

13. Am. J. M. Sc., Phila., XCVIII, 585.

14. Brain, Lond., II, 415 and 134.

15. J. Nerv. and Ment. Dis., March, 1890.

16. Univ. Med. Mag., June, I8go.

17. Med. Rec., N. Y., March 12, 1892.

18. Med. Chron., Manchester, 1892.

19. J. Nerv. and Ment. Dis., Oct. 1892, 765.

20. Tr. Am. Neur. Ass., I892.

21. Jour. Nerv. and Ment. Dis., Feb., 1893, 97.

22. J. Nerv. and Ment. Dis., Sept., 1895, 465.

23. Chorea Chronique, Paris, 1889.

24. Med. News, Phila., XLIII, 1883, 200.

25. Schmidt's Jahrbucher, June 15, 1893. Quoted in Dercum's Text-Book of Nervous Diseases, 256.

26. Arch. f. Psych. u. Nerv., Bd. XXX, Heft I.

27. Centralbl. f. innere Medicin, 1894, 918.

28. Virchow's Archiv, Bd. CXXXIX. Abs. in Neurol. Centralbl., May 15, 1895.

29. Brain, Lond., 1897, XX, 22. 